\title{
Sport as a social phenomenon
}

\author{
Yuri Naumenko ${ }^{1, *}$ \\ ${ }^{1}$ Volgograd State Academy of Physical Culture, 400005, 78 Lenina ave., Volgograd, Russia
}

\begin{abstract}
The purpose of the paper is to develop a theoretical and methodological justification for the pedagogy of sport as an independent direction in the scientific study of general pedagogy. Methods include the analysis of the socio-cultural phenomenon of "sport (sport activity)" using the conceptual provisions of social philosophy, the sociology of labor and the socio-cultural concept of health formative education ( $\mathrm{Yu}$. V. Naumenko). Results. The socio-cultural difference of close (but not related) phenomena of "physical culture" and "sport (sports activity)" is substantiated in the paper. A new socio-cultural interpretation of the concepts of "sport (sports activity)", "sports competitions" and "sports training" as manifestations of the universal human culture is proposed. The content of humanistic, creative and value-regulating functions of sports (sports activity) as a part of the universal culture is revealed. The author describes the person-oriented and the resource-pragmatic attitudes to sport (sports activity) and their manifestation in practice (in particular, in relation to children's sports). It is proved that the socio-cultural phenomenon of "sport (sports activity)" is a manifestation of labor (professional) activity in the social and humanitarian sphere, which is both a subject to the general laws of labor activity and possesses specific features. The object and subject of studying the pedagogy of sports (sports activity) as an independent direction of general pedagogy are formulated. The research problem and theoretical and practical tasks of sports pedagogy (sports activity) are specified.
\end{abstract}

Sport (sports activity) has undoubtedly grown from physical culture (physical culture exercises), but it is an independent and objectively existing socio-cultural phenomenon, which is not always justifiably associated with physical culture. The fundamental difference between sport (sports activity) and physical culture (athletic and recreational activities) is, in our opinion, the compulsory competition for comparing the sportsmen achievements (individual, group or society as a whole) with the achievements of competitors. Physical exercises (athletic and recreational activities) are aimed at personal improvement of one's body, and possible competitions are necessary only as a means of objectifying personal perceptions about one's abilities at a given time. Therefore, participation in competitions is not the goal of physical culture (athletic and recreational activities).

As rightly noted by V.I. Stolyarov and others [1, 3, 7, 8, 9], different worldview positions are in the basis of physical culture (athletic and recreational activities) and sports (sports activities). At the heart of physical culture is the awareness of the need of physical

* Corresponding author: naymenko.yv@yandex.ru 
activity for the improvement and transformation of the natural body into a socio-cultural body, but the worldview foundation of sport (sporting activity) is humanely oriented competition in sports contests as a manifestation of wider rivalry in human life in general.

However, the value and semantic (worldview) isolation of sport (sports activity) from physical culture (athletic and recreational activities) was relatively recent and not immediate that, in our opinion, explains some confusion in terminology and in determining the subject of pedagogical research in relation to sport (sports activities).

The analysis of historical and cultural research literature (V. V. Alekseev, T. Yu. Bystrova, L. B. Vozhaeva, D. M. Volodikhin, O. I. Gan, P. S. Gurevich, P. V. Danilin, M. S. Kagan, Yu. N. Solonin, A. I. Utkin, A. V. Filippov, etc.) shows that the active formation of sports (sports activity) as an independent socio-cultural phenomenon began in the second half of the $20^{\text {th }}$ century with an aggravation of the confrontation of the USSR and the USA, and the rapid development of new forms and means of mass media. The specific social functions of sport (sports activity) as a socio-cultural phenomenon associated with completion acquired a new and relevant sound in connection with attempts to transform sports (sports activity) into an effective means of political struggle and state opposition (rivalry).

In particular, analyzing the recent events related to the Summer Olympics in Rio de Janeiro and the Winter Olympics in Pyeongchang, we have to state that the Olympic Games are actually used as an instrument of international politics, when a negative image of sportsmen of another state and social system is formed, and a sort of "proceedings" and bans on participation in international competitions are introduced.

Of course, all these facts must be perceived as negative, adversely affecting the development of sports. However, in our opinion, they objectively testify to the existence of sport (sports activity) as an independent self-valuable socio-cultural phenomenon. Therefore, we believe that the concept of "sport is outside politics" is an illusion and selfdeception. It is necessary to talk about the ideological value-oriented humanistic orientation of sports and, accordingly, to realize it in everyday sports activities as opposed to really existing and advancing anti-human orientation.

However, the promotion of ideas of the worldview value-humanistic orientation of sports (sports activities) is impossible without an unambiguous clear definition of the essence of sport (sports activity) as a socio-cultural phenomenon.

By analogy with the definition of socio-cultural phenomenon of physical culture (athletic and recreational activities) proposed by us earlier $[5,6]$ and based on the above ideas about sport (sports activity), we formulate the following essential value-semantic content of socio-cultural phenomenon of "sport (sports activities)".

Sport (sports activity), like physical culture (athletic and recreational activities), is a part of universal culture, but it formulates a historically changing value attitude toward selfexpression in competition in sports contests based on the use of a specific socio-cultural corporeality, consciously and actively formed by the subject of sports activity (individual or a group) with the help of physical exercises.

The proposed essential understanding of the socio-cultural phenomenon of "sport (sports activity)" corresponds to the ideas of the majority of domestic researchers in the field of the philosophy of sport and physical culture (I. M. Bykhovskaya, N. N. Vizitei, A. G. Egorov, S. I. Kurilo, A. S. Lebedev and Yu. A. Lebedev, A. M. Leontiuk, D. V. Nikishin, A. A. Peredelsky, N. A. Ponomarev, M. Ya. Saraf, V. I. Stolyarov and others) [1, $2,3,4,7,8]$. We have tried to combine the essential characteristics of sport (sports activity), allotted by all researchers, into a consistent whole: a rivalry based on the use of corporality and an active conscious formation of individual corporeality with the help of physical exercises. 
Sports competitions, as a manifestation of the universal culture, are historically changing forms of competition between the subjects of the competition (one person with another, one group of people with others, etc.; a man with some forces of nature, with an ideal standard, etc.), which occur, as a rule, in special artificially created and conditional game situations (with venue, rules, judges and necessary technical means) in order to determine the winner as a result of effective use of the socio-cultural corporeality in particular concrete form of physical activity.

Sport training (sports preparation), as a manifestation of the universal human culture, is a historically changing active and purposeful process of formation of an individual sociocultural corporeality of the subject of sports activity (individual or a group one) to participate in a certain kind of sports competitions in order to achieve the desired result.

Sport (sports activity) as a part of the universal culture realizes its basic functions (humanistic, creative and value-regulative), which acquire specific content.

The greatest debate in the scientific and journalistic literature is connected with the realization of the humanistic function of sport (sports activity) as a socio-cultural phenomenon and a part of the universal culture.

Most domestic and foreign researchers (V. K. Balsevich, N. N. Vizitey, A. G. Egorov, A. A. Isaev, L. I. Lubysheva, N. I. Ponomarev, M. Ya. Saraf, V. I. Stolyarov, K. Heinila, Z. Krawczyk, H. Lenk, P. McIntosh, etc.) note the huge humanistic potential of sports (sports activity) and simultaneously state the strengthening of its anti-human character in recent decades, discrediting the ideas of Olympism. At the same time, most of the negative antihuman phenomena in sports (sports activities) are attributed not to the nature of sport as such, but to those features that it acquired under the influence of general socio-economic situation in modern societies and the dominant system of values (thereby confirming its socio-cultural essence).

In particular, in most developed countries of the world a consumer society has formed, and sports (sports activities) came under the influence and control of the show business industry. Along with the commercialization of sports (sporting activities), incompatible with the ideals of Olympism, the main anti-humanitarian phenomena include the growing intensity of competition, hostility in the process of sports training and in gaming behavior, doping falsification of results, sport fanaticism (often growing into vandalism), subjectivity of judges, and the increasing use of sports activities for political and ideological purposes.

Summarizing different approaches to strengthening the humanistic orientation of sport (sports activity), we have identified the following characteristics of the realization of the humanistic function of sport (sporting activity) as a part of the universal culture: a) clarification, propaganda and unconditional observance of the Fair Play principle in sports competitions of any kind and level; b) a variety of forms, content and humanization of the rules by competitive activity with the aim of involving the greatest number of those who wish.

In order to strengthen the humanistic orientation of sports (sports activities), some foreign researchers (T. Veblen, P. Bourdieu, A. Gramsci, T. Adorno, N. Elias, E. Dunning, etc.) propose to refuse to compete in contests by turning them into festivals of individual achievements without determining the winner. We believe that in this case it will be possible to talk about turning sport into a circus art.

Characteristics of the realization of the creative function of sport (sports activity) as a part of the universal culture are the following: a) to give young people a socially oriented program of personal improvement in which sporting achievements are interpreted as evidence of the advantages of a certain way of life; $b$ ) to offer the population the option of meaningful and socially valuable use of free time (also from the entertaining and spectacular point of view); c) to distract the population from real life problems, to serve as a means of psycho-emotional relaxation and stabilization of public life; d) to promote the 
unification and socialization of society, to contribute to strengthening the image of the state and national prestige through the successful performance of athletes in international competitions; e) to use sports competitions to promote interethnic and intercultural communication; e) to attract athletes as a separate social and public group to participate in public events and social actions.

The content of the value-regulating function of sport (sports activity), as a part of the universal culture, is actively developed by both domestic and foreign researchers (V. K. Balsevich, I. M. Bykhovskaya, N. N. Vizitei, B. R. Goloshchapov, G. D. Gorbunov, R. M. Zagainov, L. A. Zelenev, V. V. Kim, Yu. A. Lebedev, L. I. Lubysheva, V. I. Lyapkalo, L. P. Matveev, V. B. Mezhuyev, S. D. Neverkovich, A. A. Peredelsky, P. A. Rozhkov, M. Ya. Saraf, V. V. Stolbov, V. I. Stolyarov, B. Billater, H. Hoppeler, D. D. Blume and others) [1, $2,3,4,7,8]$.

In the majority of modern domestic studies, the value-regulative function of sports (sports activity) distinguishes $[5,8,10,12]$ the following aspects: a) the social values of sport (sports activity), which include special knowledge in the field of improving the physical qualities of the human body, sports equipment, technologies of sports training, methods of recovery, the best examples of physical activity and sports achievements; $b$ ) the individual-personal level of perception of the values of sport (sports activities), which include valeological knowledge, physical improvement skills and the ability to selforganize a healthy lifestyle, and socio-psychological settings of human mobilization activity.

Without contesting the importance of the proposed system of values of sports (sports activity), we would note that this set of values is designed on the basis of the aggregate (non-hierarchical unification of consistent elements complementing each other), which allows infinitely expanding and supplementing the set of values by including new ones, and it does not allow identifying the main direction of development of the whole system. With such an aggregate, the system of values expands in all directions in a roughly equivalent way. At the same time, the discussion on the topic "Why do sports values (sports activities) not always work in real life?" can go on indefinitely, confirming the following "axiom" sport (sports activity) is inherently self-important in nature, and only individual coaches and athletes cannot (or do not want) accept its values, so we observe various anti-human and non-value manifestations in real sports life.

Another approach is also possible, which is promoted by V.I. Stolyarov and his followers $[7,8]$ and which we support. When considering the value bases of the sociocultural phenomenon "sport (sports activity)", one must proceed from the principle of consistency (inclusion of a new element in the system is possible only if it corresponds to the hierarchical subordination of the main system-forming element). This approach presupposes reliance on the essential content of the socio-cultural phenomenon "sport (sports activity)" in determining its value system, in contrast to the approach based on the principle of aggregation, when any value is initially recognized as appropriate to sports (sports activity), and it is only necessary to justify this "conformity".

In particular, if sport (sports activity), as a part of the universal culture, expresses a historically changing value attitude to self-expression in rivalry in sports competitions on the basis of the use of a specific socio-cultural corporeality, then the attitude to rivalry is the system-forming value of sport (sport activity). It is the attitude to rivalry that determines the whole system of values of sports activity and its human and anti-human character, in particular.

It was the humane attitude to rivalry that Pierre de Coubertin, the founder of the modern Olympic movement, tried to build on a sport philosophy. Striving for victories and higher achievements, he considered as one of the conditions for the development of sports and believed that a refusal from the competition is a utopia. However, in the opinion of 
Coubertin, not the desire to set a record and to win at any cost should become the meaning of sports (sports activity). Coubertin pointed out that the most important thing in a sports contest is not a victory over an opponent, but courage and bravery in the course of the struggle for it. The spirit of struggle (and not the call of reward), in the opinion of Coubertin, induces man to perfection, to overcoming himself, his weaknesses and shortcomings. In this respect, the title of one of the articles of Coubertin is characteristic: "Win yourself!".

Thus, the person-oriented attitude to sport (sports activity) is based on the ideas put forward by Pierre de Coubertin, that sports rivalry creates the best conditions for knowing oneself and for one's abilities (both physiological and personal) in order to organize a more effective process of self-improvement.

From the standpoint of a person-oriented approach to sport (sports activity), winning a sports event is just an objective social statement that today (in this particular competition) the winner athlete has reached more significant heights in his self-improvement.

That is why, in the opinion of Coubertin, sports (sports activity) in an international scale can become the most important universal social mechanism of communication between cultures, a way of establishing peaceful relations between states, of strengthening friendship and mutual understanding among peoples, and of their cultural cooperation.

Another approach to sporting rivalry is also possible, which was most clearly formulated by the well-known football coach from the USA V. Lombardi: "Victory is not the most important thing, but victory is the only thing worth fighting for" [8].

With such a resource-pragmatic attitude to sport (sports activity), sports rivalry creates the best conditions for determining success in improving the psycho-physiological capabilities of the athlete. Victory is not only a personal result of an athlete and a coach, but also an indispensable guide in the organization of athletic training for other athletes and in assessing the professional activity of coaches.

In other words, in a person-oriented approach to sports competitions, rivalry is necessary to identify the individual capabilities of the athlete and determine the directions of self-improvement. In resource-pragmatic terms, only in competition with others it is possible to prove the individual superiority of the athlete and the superiority of the training methodology of the coach. With a person-oriented approach to rivalry in sports, every person has prospects in sports (sports activity), and with resource-pragmatic approach, there will always be unpromising athletes.

Given the above approach to the socio-cultural phenomenon of "sport (sports activities)" can the "Hamlet issue" of children's sports - To be or not to be? - be methodologically correctly resolved?

Today, the discussion between the supporters of children's sports (V.V. Belorusova, I.N. Reshetny, A.P. Rodionov, A.A. Ter-Ovanesyan, I.A. Ter-Ovanesyan, etc.) and their opponents (E.J. Adashkevichene, K. Sheriff and M. Sheriff, etc.) is going on at the level of searching for new "more convincing" evidence in defense of one's positions, and the valuesemantic aspect is not considered.

The value-semantic attitude to competition in sports contests is at the heart of various forms of the existence of children's sports, as well as great sport.

If the organization and content of a specific form of children's sports are based on a person-centered attitude toward competition, we can confidently and reasonably assert that active sports allow children becoming confident, competitive, and developing selfdiscipline, interaction, motivation for achievement, courage, and perseverance. This sport creates an environment, in which the child can develop a positive self-image and gain additional confidence in his abilities, helps to develop a spirit of cooperation between groups of individuals. Participation in sports events also contributes to the development of a correct attitude towards victories and defeats. 
If the organization and content of a particular form of children's sports is based on the resource-pragmatic attitude to competition, we can just confidently and reasonably assert that the inclusion of children in rivalry negatively affects their personal development, leads to the development of selfishness, aggression, envy, hatred to rivals, as well as intrapersonal and interpersonal conflicts, to stress, etc. In addition, many young sportsmen receive a stable set-up for victory at any cost (even at the expense of health), because to win means to demonstrate their superiority over others, to win valuable prizes, rewards, to obtain other material victory-related wealth, to gain fame, etc.

Thus, when evaluating the specific forms of organization and content of children's sports, we cannot concentrate our attention solely on the psycho-pedagogical competence of the coach and the shortcomings of educational work. In fact, this is about a manifestation of a certain type of value-semantic relation (conscious or unconscious) to rivalry, which determines the methodology of young athletes training.

From the standpoint of sociology, the socio-cultural phenomenon of "sport (sports activity)" is a manifestation of labor (professional) activity in the social and humanitarian sphere, which is subordinate to both general laws and specific features.

This statement is based on the analysis of works on the sociology of labor (B. M. Genkin, O. V. Romashov, M. P. Lukashevich, N. A. Seroshtan, etc.), confirming that the socio-cultural phenomenon of "sport (sporting activities)" meets the basic characteristics of a labor (professional) activity, such as: a) relatively long, independent performance of certain activities (sports training and participation in sport events) as opposed to athletic and recreational activities that can have non-permanent and short-term character; b) it requires special education and special skills necessary for successful participation in a certain type of sport events, in addition to general psycho-physiological and medical ideas about psychosomatic health and methods of its strengthening; c) it forms a certain professional behavior (professional self-awareness, professional motivation, professional ethics, models of professional actions), having both common features and specific ones depending on the sport (sports activity); d) is manifests itself in personal professional deformities related to the specifics of sport (sports activity), which are not characteristic of physical culture and recreation activities; e) is manifested in the special status of representatives of sports (sports activities) in the public consciousness (including the level of laws and other official regulatory documents), which is also not typical for physical culture and recreation.

The object of sports activity (sport) as a labor (professional) activity in the social and humanitarian sphere is the psychophysiological and personal changes in the subject of sports activity (individual or group) that ensure the success of participation in a certain kind of sports competitions.

The subject of sports activity (sport) as a labor (professional) activity in the social and humanitarian sphere is sports training, the process of conscious and active formation of a specific socio-cultural corporeality by the subject of sports activity (individual or group).

The result of sports activity (sport) as a labor (professional) activity in the social and humanitarian sphere is an individual success in a certain kind of sports competitions, which objectifies the effectiveness of sports training focused at the formation of a specific sociocultural corporeality.

In the specialized scientific and methodical literature on the problems of the content, organization and evaluation of the effectiveness of sports training, various indicators are used, such as the level of development of physical abilities, the levels of development of sports technical and sports-tactical readiness, the level of psychological preparedness, etc. All these indicators are of objective nature, but each of them fixes only the probable possibility of successful performance in sports competitions. Therefore, they should be regarded as particular subject indicators of the likelihood of achieving the result of sports 
activities (sports) as a labor (professional) activity. The only indisputable and objective indicator of the effectiveness of sports activities is the result shown by the athlete at the competitions.

Specific characteristics of sport (sports activity) as a labor (professional) activity in the social and humanitarian sphere are the following: a) early start and early termination of doing sports (sports activities) compared to other types of work (professional activity); b) doing sports coincides with the period of active development of the psyche and the formation of the personality of the subject of sports activity; c) doing sports (sports activities), as a rule, are accompanied by injuries (physical and psychological).

The above specific features of sports (sports activities) as a labor (professional) activity in the social and humanitarian sphere lead to the following significant socio-cultural issues: a) social (including labor) adaptation of athletes after the end of a sports career; b) problems of possible personal deformation as a consequence of the traumas suffered and psychological and personal unpreparedness for early engagement in sports (sports activities).

These problems, in our opinion, should be reflected in the object and subject of the study of the pedagogy of sports (sports) as an independent direction of general pedagogy.

In particular, based on the fundamental concepts of classical general pedagogy (N.V. Bordovskaya and A.A. Rean, V.A. Slastenin, I.F. Isaev and E.N. Shiyanov, V.I. Smirnov, etc.), we believe that the subject of studying the pedagogy of sports activity (sport) of physical culture, as a sector of general pedagogy, is the vocational education (professional training) of a person for sporting activities, as an obligatory part of the universal function of a man on transferring the socio-cultural heritage to the younger generation and teaching how to preserve and increase it.

Consequently, the subject of studying pedagogy of sports (sports activity) as a sector of general pedagogy can only be a holistic integrative pedagogical process of organizing the learning of specific knowledge and skills (sports training) of those who do sport, and pedagogical support for their personal development in the process of doing sports as a labor (professional) activity in the social and humanitarian sphere.

The scientific problem of the pedagogy of sport (sports activity) is how to organize effective sports training for sportsmen that guarantees the success of their performance in sports competitions, and pedagogical support of their personal development that minimizes the risks of social disadaptation?

The theoretical task of the pedagogy of sports (sports activity) is revealing the regularities of the pedagogical process of sports training for those engaged in sports; regularities of pedagogical support of personal development engaged in sports in the process of sports training and participation in sports competitions; patterns of mutual influence and mutually conditioned improvement and increasing the effectiveness of the process of sports training for those engaged in sports, and pedagogical support for their personal development.

The practical task of the pedagogy of sports (sports activity) is to translate the established patterns and regularities into the language of law, rules and technologies for the systematic use by trainers.

Humanistic and personally-oriented focus of the pedagogy of sport (sports activity) will manifest itself in various concepts, theories and technologies of sports training in the form of a value-semantic relation to sports competitions as a rivalry that creates the best conditions for knowing oneself, for oneself capabilities (both physiological and personal) in order to more effectively organize the process of self-improvement.

\section{References}


1. M. A. Zakharov, Sociology of sports: an educational-methodical manual (2nd ed.) (SGAFKST, Smolensk, 2008)

2. Yu. F. Kuramshin, Sports higher achievements, their socio-cultural values, and antivalues: the theoretical and methodological aspect (GFFC, St. Petersburg, 2002)

3. L. I. Lubysheva, Sociology of physical culture and sports (3rd ed.) (Publishing Center Academy, Moscow, 2010)

4. L. P. Matveev, The general theory of sport and its applied aspects: proc. for the final level higher. physical culture (Soviet Sport, Moscow, 2010)

5. Yu. V. Naumenko, Domestic and Foreign Pedagogics, 14, 5 (2013)

6. Yu. V. Naumenko, Vestnik MSU: Series 20 Pedagogical Education, 3 (2015)

7. V. I. Stolyarov, Modern problems of sciences in Physical Culture and Sport: philosophy of sports (Soviet Sport, Moscow)

8. V. I. Stolyarov, Sociology of Physical Culture and Sports: a textbook (Flint/Science, Moscow, 2004)

9. V. D. Fiskalov, Theoretical and methodological aspects of the practice of sports: a textbook (Sport, 2016) 